\title{
Improving the means and methods of training of young fencers aged 9-11 years
}

Irina Kriventsova $^{1 \mathrm{ABCDE}}$, Yevgeniy Gorbachuk ${ }^{1 \mathrm{ABCD}}$, Svitlana Chernihivska ${ }^{2 \mathrm{BCDE}}$, Marina Jagiello ${ }^{3 \mathrm{BCD}}$, Abdelkrim Bensbaa ${ }^{4 \mathrm{BCDE}}$

${ }^{1}$ H.S. Skovoroda Kharkiv National Pedagogical University, Ukraine

${ }^{2}$ Department of Physical Education and Sports, Dnipro University of Technology, Ukraine

${ }^{3}$ Gdansk University of Physical Education and Sport, Poland

${ }^{4}$ Military Center of Sport Training, Abu Dhabi, United Arab Emirates

Author contributions: A - Study design; B - Data collection; C - Qualitative analysis; D - Manuscript preparation; E Funds Collection

\begin{tabular}{|c|c|}
\hline \multicolumn{2}{|l|}{ Abstract } \\
\hline $\begin{array}{l}\text { Background } \\
\text { and Study Aim }\end{array}$ & $\begin{array}{l}\text { Training of motor actions of young athletes requires consideration the peculiarities of the sensitive period } \\
\text { of their development. An important component of the training program is the use of training tools that } \\
\text { do not harm the health of young athletes. The purpose of the study is to identify the dynamics of physical } \\
\text { training and provide an assessment of technical and tactical techniques of fencers (sword) aged 9-11 years } \\
\text { under the influence of the author's program. }\end{array}$ \\
\hline $\begin{array}{l}\text { Material and } \\
\text { Methods }\end{array}$ & 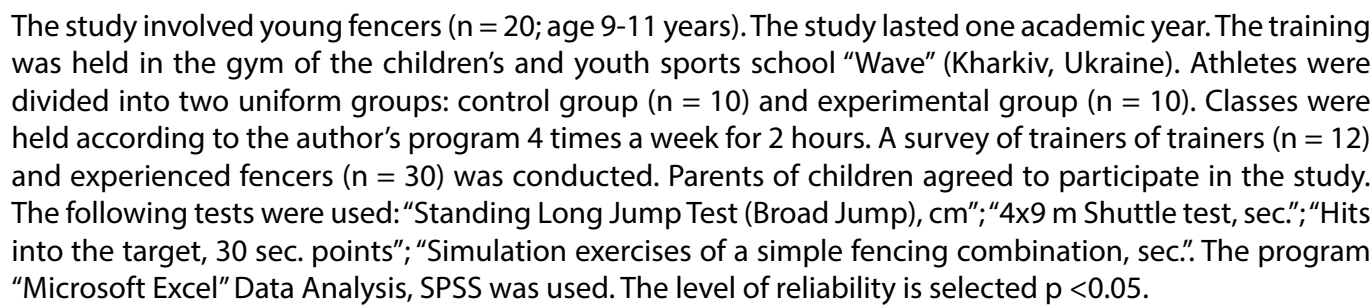 \\
\hline Results & $\begin{array}{l}\text { Significant changes in the indicators of the control group were obtained: "Standing Long Jump Test (Broad } \\
\text { Jump), } \mathrm{cm} \text { ", }(\mathrm{p}<0.05) \text {; in the test " } 4 \times 9 \mathrm{~m} \text { Shuttle test, sec." }(\mathrm{p}<0.05) \text {; both tests have assessment of technical } \\
\text { and tactical techniques }(\mathrm{p}<0.01) \text {. In the experimental group, all tests showed positive changes }(\mathrm{p}<0.01) \text {.) } \\
\text { In comparison of two groups with each other in the tests "Standing Long Jump Test (Broad Jump), } \mathrm{cm} \text { ", } \\
\text { " } 4 \times 9 \mathrm{~m} \text { Shuttle test, sec." and "Hits into the target, } 30 \text { sec. points" there were positive statistically significant } \\
\text { changes }(p<0.05) \text {. In the test "Simulation exercises of a simple fencing combination, sec." no significant } \\
\text { changes occurred }(p<0.05) \text {. }\end{array}$ \\
\hline Conclusions: & $\begin{array}{l}\text { It is recommended to take into account the effects of exercise on the health of young athletes when } \\
\text { designing a fencing training program. }\end{array}$ \\
\hline Keywords: & \\
\hline
\end{tabular}

\section{Introduction}

The training of young athletes aims to achieve sports results. However, training programs do not always take into account the impact of exercise on the health of young athletes. In the pursuit of results coaches sometimes neglect the health component in building the training process. Therefore, it makes sense to consider the positions of various specialists in fencing on this issue.

Earlier studies have proposed a special set of fencing exercises to expand the arsenal of fighting, as well as the behavior of athletes in unexpected situations [1]. The authors note the need to motivate athletes. This approach should be in the training programs of young athletes.

Building a safe training process takes into account the various components of training. Among them is the formation of young athletes' negative attitudes towards doping. Also, indicate the health consequences of such athletes' behavior. In a study by Poppel et al. [2] it is noted

\footnotetext{
(c) Irina Kriventsova, Yevgeniy Gorbachuk, Svitlana Chernihivska, Marina Jagiello, Abdelkrim Bensbaa, 2021 doi:10.15561/26649837.2021.0608
}

that coaches play a significant role in the attitude of young fencers (swords) to their own health. The authors offer their own views on the role of the coach in the prevention of doping by young athletes. In this aspect, Mroczkowska [3] believes - "The assessment of objective risk depends more on the rank of what may be lost (health) than on what may be gained (medals)." The author analyzes the possible losses in the use of doping by young athletes. Among such losses is the risk of declining health of young athletes in the early stages of training [3]. An equally important component of the health of young athletes is the compliance of loads with the initial periods of training. In this context, the health component should be present in training programs.

Another area of design training programs for young fencers is the methodological basis for the development of motor skills. Movshovich et al. [4] reveal the methodological foundations for the development of coordination skills of young fencers. The authors believe that the main principle of technical development in the training process of young athletes should be considered 
mastering the performance of fencing movements with maximum variability, rather than maximum speed.

Specialized training of young athletes has its risks. Among them are the risks of injury due to overload. This is confirmed in studies of different orientations $[5,6]$. In general, the authors agree that excessive workload is the result of poor construction of the training program. The authors believe that aerobic exercise is more appropriate in the early stages of training young athletes.

It is known that a complex combination of a large amount of training and academic requirements can hinder the cognitive and academic results of young athletes. Granacher et al. [7] believe that the complex combination of a large amount of training and academic requirements can hinder the cognitive and academic performance of young athletes. The authors offer a program of school 1-year sports training in combination with physical education. The use of such a program improved physical fitness, but did not negatively affect the cognitive and educational performance of young athletes.

Malina et al. [8] investigated the relationship between invasive and non-invasive indicators of biological maturation in young athletes. The authors propose to include in the skills development programs the classification of young people into early, middle and late maturity status. This will improve the quality of training programs and competitions. Detanico et al. [9] consider it necessary to take into account indicators of somatic maturation, growth and training experience in training programs for young athletes.

Another study proposes to include a combination of game training and high-intensity interval training in the training program [10]. Sharma et al. [11] consider it necessary to conduct cardiac screening before the participation of young athletes in sports competitions. Such screening should be voluntary, not mandatory, and performed by experienced physicians.

Gaining fencing experience is impossible without the development of physical qualities, as well as mastering the technical and tactical techniques of fencing. The means and methods of the educational and training process must be constantly improved and correspond to modern trends in the development of the sport. This should be the basis for acquiring and improving the level of fencing skills [12-14].

The purpose of the study: to investigate the dynamics of physical training and provide an assessment of technical and tactical techniques of fencers aged 9-11 years under the influence of the author's program.

\section{Material and Methods}

\section{Participants.}

Under observation were fencers $(\mathrm{n}=20$; age 9-11 years) of the basic training group, who train in the gym of the children's and youth sports school "Wave" (Kharkov, Ukraine). Athletes were divided into two uniform groups: control group $(\mathrm{CG} ; \mathrm{n}=10)$ and experimental group (EG; $\mathrm{n}=10$ ). Classes were held 4 times a week for 2 hours. In EG classes were conducted according to the author's program. A survey of coaches and experienced athletes was conducted $(n=42)$. The children's parents agreed to participate in the study. This study was approved by the Bioethics Committee for Clinical Research and conducted according to the Declaration of Helsinki.

Research design.

The study lasted one academic year. A survey of coaches and experienced athletes was organized. The purpose of the questionnaire is to identify the main areas of overcoming shortcomings in the training of young fencers.

The control group was engaged in the standard program for children and youth sports school fencing department (4 times a week for 2 hours) [15]. The experimental group worked on the author's program 4 times a week for 2 hours. The content of the author's program differed from the standard set of special exercises.

The author's program consists of special jumping exercises; exercises with sports tires; mobile games with fencing equipment; sets of exercises and maneuvers in the battlefield; special exercises on the target.

Assessment of physical fitness of young fencers was carried out according to the following standard tests: "Standing Long Jump Test (Broad Jump), cm"; "4x9 m Shuttle test, sec." [16]. Testing was conducted at the beginning of the experiment. Retesting was conducted at the end of the experiment.

Evaluation of the implementation of technical and tactical techniques was carried out according to such tests as:

1) "Hit into the target, 30 sec. points" (Fig. 1):

- used a target that is equipped with 5 marks of different diameters (the smallest - 25 points, the largest - 5 points);

- starting position of the athlete - short distance;

- hits are performed on the target. The result is the number of points scored in 30 seconds. The attempt is not credited if the participant has never hit the mark on the target within 15 seconds.

2) "Simulation exercises of simple combination, sec." (Fig. 2):

- steps: forward-jump; forward- lunge;

- steps back- lunge;

- leap forward- lunge;

- backwards-fleche attack.

The athlete gets on a guard position, puts leg (front leg) on the line. On command, the athlete performs:

1- steps forward: as soon as the leg (front leg) crosses the line, the athlete performs a leap forward- lunge;

2- steps back: as soon as the leg (front leg) crosses the line, the athlete performs a lunge;

3- jumps forward: as soon as the leg (front leg) crosses the line, the athlete performs backwards-fleche attack;

4- jumps back: as soon as the leg (front leg) crosses the line, the athlete performs a fleche-attack.

The result is runtime of one combination. An attempt can not be counted if the athlete performed the attack before crossing the line.

3) "Complex reaction with a choice, sec." (Fig. 3)

The athlete gets on a guard position. The cones are 

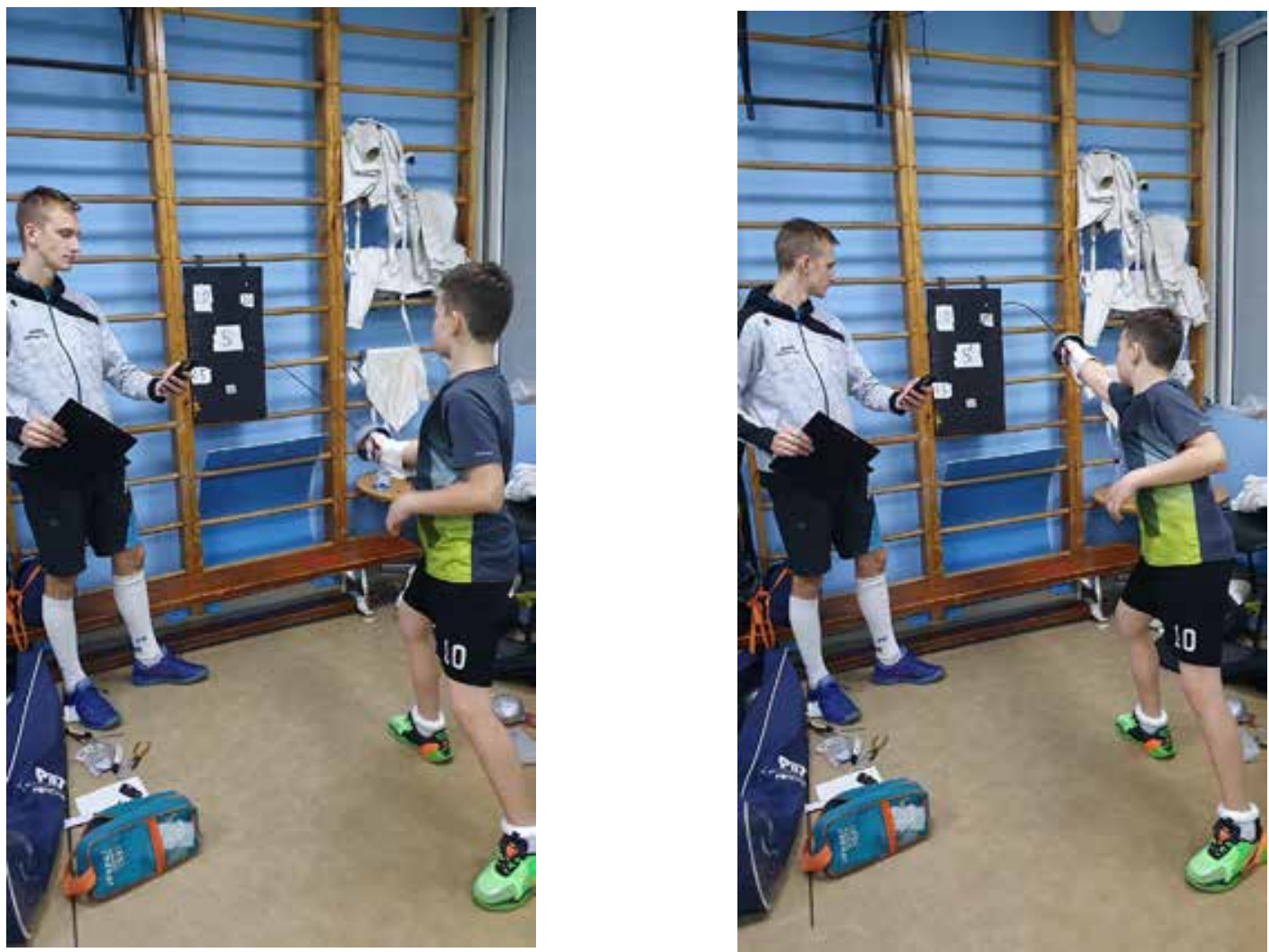

Figure 1. Test "Hits into the target, $30 \mathrm{sec}$. points" (photo - Irina Kriventsova)

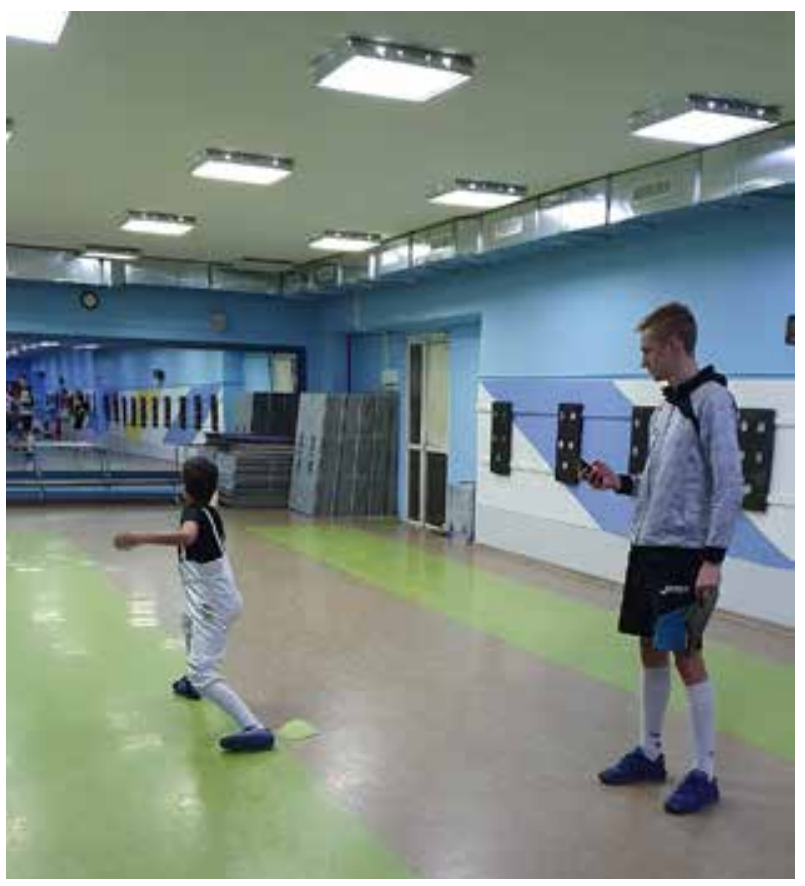

Figure 2. Test "Simulation exercises of simple combination, sec." (photo - Irina Kriventsova)

placed in front, behind, to the right and to the left at a distance of 2 meters on all sides of the participant. Depending on the placement (side) of the cone (front, back, left, right), the corresponding option of moving to it is performed: in front - steps forward; behind - jumping forward; on the left - steps back; on the right - jumping back. The coach step by step naming the parties freely.

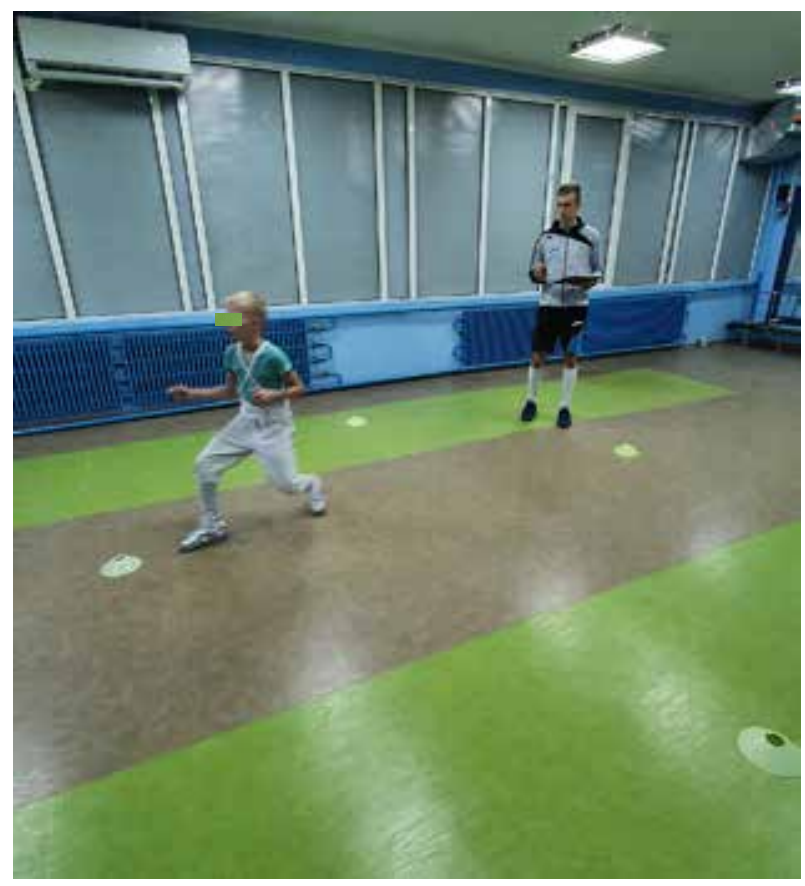

Figure 3. Test "Complex reaction with a choice, sec."

The athlete must react as quickly as possible: perform the appropriate movement option and go beyond the line of a certain cone. If the direction of the athlete's starting position does not coincide with the direction of movement, he/she must jump to take the correct starting position. The result is the average latency reaction time (the time from the moment when a certain side was named 
to the beginning of the participant's movement) for 3 attempts. Remarks: the participant must keep the guard position when moving; legs should not be straightened while performing movements. An attempt can not be counted if the participant has incorrectly completed the appropriate movement option.

Statistical analysis. The program "Microsoft Excel" Data Analysis, SPSS was used. It was determined the following indicators: standard deviation, the reliability of the differences between the parameters of the initial and final results and between CG and EG (Student's t-test). The level of reliability is selected $p<0.05$.

\section{Results}

According to the results of the survey of coaches and experienced athletes, it was found that the main areas of overcoming shortcomings in the training of fencers are:

- inclusion in the training process of strength training, stretching, jumping exercises, exercises on special devices, exercises to prevent typical injuries;

- improvement of material and technical support of the sport, assistance of the state and/or sponsors in financing the participation of athletes in ranking competitions;

- involvement of assistant coaches in providing individual lessons in fitness and other types of physical training, rehabilitation, psychological training; the use of video reviews of the training of leading fencers, the use of modern devices for determining physiological parameters [17].

The dynamics of the level of general physical fitness under the influence of the developed program indicates significant changes in indicators (Table 1). In CG: "Standing Long Jump Test (Broad Jump), cm" ( $\mathrm{t}=0.014$, $\mathrm{p}<0.05)$; " $4 \mathrm{x} 9 \mathrm{~m}$ Shuttle test, sec." $(\mathrm{t}=0.021, \mathrm{p}<0.05)$; in both tests of assessment of technical and tactical techniques $(\mathrm{p}<0.01)$.

In comparison of two groups with each other in the tests "Standing Long Jump Test (Broad Jump), cm”, “4x9 m Shuttle test, sec." and "Hit into the target, 30 sec. points" there were positive statistically significant changes ( $p$ $<0.05$ ) (Table 1). In the test "Simulation exercises of a simple combination, sec." and "Complex reaction with a choice, sec." no significant changes occurred ( $p>0.05$ ), although there is a noticeable trend of improving the results in EG. It is possible that one year is not a sufficient period for the reliable formation of these indicators. It takes more time.

As can be seen from Table 1, the reduction of the standard deviation in the groups occurred in the tests " $4 \times 9$ m Shuttle test, sec." and "Simulation exercises of simple combination, sec.". This indicates a gradual alignment between stronger and weaker athletes in the groups.

Results of "Standing Long Jump Test (Broad Jump), $\mathrm{cm}$ " and "Hit into the target, $30 \mathrm{sec}$. points" show the increase in standard deviation. This indicates a greater discrepancy between the representatives of the group against the background of a slight and significant improvement in test results. The same tendency is observed at mastering of technique of performance of difficult exercises by separate athletes of groups.

\section{Discussion}

The study confirms the opinion of many experts in the field of physical culture and sports about the importance of health-oriented training of young athletes. McGuine et al. [18] note that health policy experts should take health indicators into account when designing and implementing policies to improve adolescent health. Baumgartner et al. [19] believe that moderate physical activity in young athletes is associated with a reduced risk of cardiovascular disease. Other studies [20-24] also emphasize the need to care for the health of children and young athletes in physical activity at various levels. The authors also note the role of parents / coaches and the benefits of gendersensitive physical activity programming. Our program also takes into account such an important component as the health of young athletes.

Table 1. Comparison of the dynamics of indicators of physical training under the influence of the program in CG and EG

\begin{tabular}{|c|c|c|c|c|c|c|c|c|}
\hline \multirow{3}{*}{ Test } & \multicolumn{4}{|c|}{ The beginning of the experiment } & \multicolumn{4}{|c|}{ The end of the experiment } \\
\hline & \multicolumn{2}{|c|}{$X \pm \sigma$} & \multirow[b]{2}{*}{$\mathbf{t}$} & \multirow[b]{2}{*}{$\mathbf{p}$} & \multicolumn{2}{|c|}{$X \pm \sigma$} & \multirow[b]{2}{*}{$\mathbf{t}$} & \multirow[b]{2}{*}{$p$} \\
\hline & $\begin{array}{l}\text { CG } \\
(n=10)\end{array}$ & $\begin{array}{l}E G \\
(n=10)\end{array}$ & & & $\begin{array}{l}\text { CG } \\
(n=10)\end{array}$ & $\begin{array}{l}E G \\
(n=10)\end{array}$ & & \\
\hline $\begin{array}{l}\text { Standing Long Jump } \\
\text { Test (Broad Jump), } \\
\mathrm{cm}\end{array}$ & $163.2 \pm 10.6$ & $164.7 \pm 6.7$ & 0.32 & $>0.1$ & $164.7 \pm 12.47$ & $172.7 \pm 10.07$ & 0.02 & $<0.05$ \\
\hline $\begin{array}{l}4 \times 9 \text { m Shuttle test, } \\
\text { sec. }\end{array}$ & $11.8 \pm 0.44$ & $11.94 \pm 0.51$ & 0.27 & $>0.1$ & $11.64 \pm 0.42$ & $11.2 \pm 0.42$ & 0.024 & $<0.05$ \\
\hline $\begin{array}{l}\text { Hit into the target, } 30 \\
\text { sec. points }\end{array}$ & $474.5 \pm 131.5$ & $547 \pm 82$ & 0.12 & $>0.05$ & $493.5 \pm 136.5$ & $618.5 \pm 93.5$ & 0.04 & $<0.05$ \\
\hline $\begin{array}{l}\text { Simulation } \\
\text { exercises of simple } \\
\text { combination, sec. }\end{array}$ & $12.43 \pm 1.45$ & $12.91 \pm 1.36$ & 0.17 & $>0.05$ & $12.08 \pm 1.08$ & $11.7 \pm 1.05$ & 0.29 & $>0.05$ \\
\hline $\begin{array}{l}\text { Complex reaction } \\
\text { with a choice, sec. }\end{array}$ & $1.698 \pm 0.24$ & $1.69 \pm 0.22$ & 0.49 & $>0.05$ & $1.627 \pm 0.19$ & $1.503 \pm 0.13$ & 0.15 & $>0.05$ \\
\hline
\end{tabular}


We agree with the conclusions of other authors that the development of tactical thinking is based on the ability to monitor closely, quickly analyze and make the right decision $[1,25]$. The authors note that the development and improvement of tactical skills has individual and long-term acquisition of relevant skills.

Our program was designed taking into account the need to diversify the techniques of fencers and adhere to the quality of their performance. Techniques during the fight acquire tactical meaning and become fighting operations. It is the expansion of the arsenal of hostilities that favors the fencer.

Harrison $\mathrm{CB}$ et al. [10] note that the combination of game and high-intensity interval training provides positive changes in the training of athletes. We believe that game and competitive methods are leading in the training of young athletes. That is why we have developed and adapted 8 games using fencing equipment.

Palmer-Keenan and Bair [26] note that the competitive method is a factor that can confuse competitors. We do not fully agree with this statement. In such cases, it all depends on the proper planning of exercise, which should be available to participants. In this context, our program takes into account the pedagogical principles of accessibility and adequacy of the level of physical activity of young athletes.

We agree with the opinion of other authors [4, 27, 28] that mastering the performance of fencing movements should be performed with maximum variability. However, it should be noted that when performing technical techniques, it is necessary to apply a gradual transition from the minimum rate of execution to the maximum and return to the minimum. In this case, the athlete should try to adhere to the preservation of exercise techniques.

Chtara et al. [27] note that the use of the test of change of direction for fencers is closely related to the selected indicators of physical fitness. In this context, we can say that such tests were used in our program. These tests were developed and tested by us with the participation of young athletes and they differed slightly from the standard ones offered by the program for sports schools.

An important element of our program is the special attention to the implementation of fleche technique. This attack is also analyzed in the study of Fatemeh [29]. The author presents estimates of biomechanical indicators of fencing athletes according to the criteria of ankle injury during landing after fleche technique. It is stated that professionals should pay attention to the balance of muscle strength before tournaments. We fully agree with this statement. However, it should be noted that the correct technique of performing a complex fleche attack should be gradually formed in young fencers under the careful control of the coach.

Our results prove that under the influence of the author's program there were positive changes in the indicators of all selected tests. Tests on general physical fitness and hits into the target are reliable $(\mathrm{p}<0.05)$. And tests on the implementation of simulation exercises and the composition of the reaction of choice have a tendency to improve. This indicates a long-term acquisition of relevant skills.

\section{Conclusions}

The author's program was aimed at diversifying the educational and training process at the stage of initial specialization. The program is based on the expansion of jumping exercises, complex coordination exercises, exercises for stretching muscles, methods of manoeuvring in the fighting stance, exercises on the target.

It is recommended that the effects of exercise on the health of young athletes be taken into account when designing a fencing training program.

\section{Conflict of interest}

The authors report no conflict of interest.

\section{References}

1. Kriventsova IV, Limans'kij PP. Dynamics of indicators of combat effectiveness of fencers aged 10-12 years under the influence of the author's program. Edinoborstva, 2020;4(18):16-24. (In Ukrainian).

2. Poppel K, Busch D. The doping critical attitude of elite sports coaches in combat sports. German Journal of Exercise and Sport Research. 2019;49(2):168-178. https://doi.org/10.1007/s12662-019-00565-6

3. Mroczkowska H. Accepted level of risk of doping use in the view of young athletes. Biology of Sport. 2011;28(3):183-187. https://doi.org/10.5604/959291

4. Movshovich AD, Lobanov VV. Methodological bases of the development of coordination abilities and exactness of hit of beginning foil fencers aged 9-10. Tomsk State University Journal. 2018(434):162-166. https://doi.org/10.17223/15617793/434/22

5. Myer GD, Jayanthi N, Difiori JP, Faigenbaum AD, Kiefer AW, Logerstedt D, et al. Sport Specialization, Part I: Does Early Sports Specialization Increase Negative Outcomes and Reduce the Opportunity for Success in Young Athletes? Sports
Health-a Multidisciplinary Approach. 2015;7(5):437-442. https://doi.org/10.1177/1941738115598747

6. Armstrong N, Tomkinson GR, Ekelund U. Aerobic fitness and its relationship to sport, exercise training and habitual physical activity during youth. British Journal of Sports Medicine. 2011;45(11):849-858. https://doi.org/10.1136/bjsports-2011-090200

7. Granacher U, Borde R. Effects of Sport-Specific Training during the Early Stages of Long-Term Athlete Development on Physical Fitness, Body Composition, Cognitive, and Academic Performances. Frontiers in Physiology. 2017;8:810. https://doi.org/10.3389/fphys.2017.00810

8. Malina RM, Silva M, Figueiredo AJ, Carling C, Beunen GP. Interrelationships among invasive and non-invasive indicators of biological maturation in adolescent male soccer players. Journal of Sports Sciences. 2012;30(15):1705-1717. https://doi.org/10.1080/02640414.2011.639382

9. Detanico D, Kons RL, Fukuda DH, Teixeira AS. Physical Performance in Young Judo Athletes: Influence of Somatic Maturation, Growth, and Training Experience. Research Quarterly for Exercise and Sport. 2020;91(3):425-432. 
https://doi.org/10.1080/02701367.2019.1679334

10.Harrison CB, Kinugasa T, Gill N, Kilding AE. Aerobic Fitness for Young Athletes: Combining Game-based and High-intensity Interval Training. International Journal of Sports Medicine. 2015;36(11):929-934. https://doi.org/10.1055/s-0034-1396825

11. Sharma S, Merghani A, Gati S. Cardiac Screening of Young Athletes Prior to Participation in Sports Difficulties in Detecting the Fatally Flawed Among the Fabulously Fit. Jama Internal Medicine. 2015;175(1):125-127. https://doi.org/10.1001/jamainternmed.2014.6023

12.Klimenchenko VG, Nesen OO, Nikitkin MD. Determining indicators of coordination abilities of young fencers. Osnovi pobudovi trenuval'nogo procesu $v$ ciklichnikh ta ekstremal'nikh vidakh sportu, 2021;5:150-156. (In Ukrainian).

13.Kriventsova IV, Klimenchenko VG, Gorban' IIu. Effectiveness of means and methods of tactical training of students-fencers. Visnik Chernigivs'kogo nacional'nogo pedagogichnogo universitetu, 2015;129(4):105-109. (In Ukrainian).

14.Fencing III (Foil) [Internet].Tulsa Fencing Club, 2014 [updated $2021 \mathrm{Feb} 5$; cited $2021 \mathrm{Feb}$ 25]. Available from: http://www.tulsafencing.com/wp-content/uploads/2018/08/ Fencing-III-foil.pdf

15.Busol VA. Fencing: training program [Internet]. Kiev, 2014 [updated 21 Jun 1; cited 2021 Jun 5]. (In Ukrainian). Available from: https://niprorada.gov.ua/upload/files/ o_1dfihabfi5ve5rr1nsk1cf61ma71a.pdf

16. Bodnar IR, Vynohradskyi BA, Pavlova YuO, Ripak MO, Dukh TI, Stefanyshyn MV. Assessment of physical fitness and health of different groups of the population. [Internet]. Lviv: LSUPC; 2018. [updated 21 Jun 1; cited 2021 Jun 5]. (In Ukrainian). Available from: http://repository.ldufk.edu. ua:8080/bitstream/34606048/19444/1/\%d0\%9e\%d1\%86 \%d1\%96\%d0\%bd\%d1\%8e\%d0\%b2\%d0\%b0\%d0\%bd\% d0\%bd\%d $1 \% 8$ f $\% 20 \%$ d $1 \% 84 \%$ d $1 \% 96 \%$ d $0 \%$ b7\%d0\%b8 $\%$ d $1 \% 87 \%$ d0\%bd $\%$ d0\%be\%d1\%97\%20\%d0\%bf\%d1\% $96 \%$ d0\%b4\%d0\%b3\%d0\%be\%d1\%82\%d0\%be\%d0\%b $2 \%$ d0\%bb\%d0\%b5\%d0\%bd\%d0\%be\%d1\%81\%d1\%82 $\% \mathrm{~d} 1 \% 96 \% 20 \% \mathrm{~d} 1 \% 82 \% \mathrm{~d} 0 \% \mathrm{~b} 0 \% 20 \% \mathrm{~d} 0 \% \mathrm{~b} 7 \% \mathrm{~d} 0 \% \mathrm{~b} 4 \%$ d0\%be\%d1\%80\%d0\%be\%d0\%b2\%27\%d1\%8f\%20\%d1 $\% 80 \%$ d $1 \% 96 \%$ d0\%b7\%d0\%bd\%d0\%b8\%d1\%85\%20 $\% \mathrm{~d} 0 \% \mathrm{~b} 3 \% \mathrm{~d} 1 \% 80 \% \mathrm{~d} 1 \% 83 \% \mathrm{~d} 0 \% \mathrm{bf} \% 20 \% \mathrm{~d} 0 \% \mathrm{bd} \% \mathrm{~d} 0 \% \mathrm{~b} 0$ $\%$ d $1 \% 81 \%$ d0\%b5\%d0\%bb\%d0\%b5\%d0\%bd\%d0\%bd\%d1 $\% 8$ f.pdf

17.Gorbachuk YV, Kriventsova IV. Analysis of the problems of the educational and training process for the training of fencers. Aktual'ni problemi fizichnogo vikhovannia riznikh verstv naselennia, 2021;1: 36-40. (In Ukrainian).

18.McGuine TA, Biese KM, Petrovska L, Hetzel SJ, Reardon C, Kliethermes S, et al. Mental Health, Physical Activity, and Quality of Life of US Adolescent Athletes During COVID-19Related SchoolClosures and Sport Cancellations:AStudy of 13 000 Athletes. Journal of Athletic Training. 2021;56(1):11-19. https://doi.org/10.4085/1062-6050-0478.20
19.BaumgartnerL, SchulzT, OberhofferR, Weberruss H.Influence of Vigorous Physical Activity on Structure and Function of the Cardiovascular System in Young Athletes-The MuCAYAStudy. Frontiers in Cardiovascular Medicine. 2019;6:148. https://doi.org/10.3389/fcvm.2019.00148

20.Exel J, Mateus N, Travassos B, Goncalves B, Gomes I, Leite $\mathrm{N}$, et al. Off-Training Levels of Physical Activity and Sedentary Behavior in Young Athletes: Preliminary Results during a Typical Week. Sports. 2018;6(4):141. https://doi.org/10.3390/sports6040141

21.Lipowski M, Lipowska M, Jochimek M, Pawel J. Exathletes as Parents Promoting Healthy Lifestyles in Their Families: The Nutrition and Physical Activity of Mothers, Fathers, and 6-Year-Old Children. Journal of Family Issues. 2021;42(11):2529-2553. https://doi.org/10.1177/0192513x20984501

22.Post P, Palacios R. Aggie Play. A Gender-Relevant Physical Activity Program for Girls. Journal of Sport \& Exercise Psychology. 2019;41(4):194-205. https://doi.org/10.1123/jsep.2018-0299

23.Tomaczkowski L, Klonowska J. Physical activity of school children and youth. Balt J Health Phys Activ, 2020;12:83-7. https://doi.org/10.29359/BJHPA.12.2.09

24.Ari E, Deliceoglu G. The examination of some anthropometric and motoric characteristics of students aged eight years according to their maturation level. Balt $J$ Health Phys Activ, 2020;12:45-63. https://doi.org/10.29359/BJHPA.12.2.06

25.Pietsch S, Jansen P. Motor affordance or gender-stereotyped nature of physical activity - what is more important for the mental rotation performance of female athletes? Journal of Cognitive Psychology. 2021;33(5):568-580. https://doi.org/10.1080/20445911.2021.1931242

26.Palmer-Keenan DM, Bair K. Research to Support the Development of a Campaign to Increase Physical Activity Among Low-Income, Urban, Diverse, Inactive Teens. Journal of Nutrition Education and Behavior. 2019;51(6):703-710. https://doi.org/10.1016/j.jneb.2019.02.001

27.Chtara H, NegraY, Chaabene H, Chtara M, Cronin J, Chaouachi A. Validity and Reliability of a New Test of Change of Direction in Fencing Athletes. International Journal of Environmental Research and Public Health. 2020;17(12):4545. https://doi.org/10.3390/ijerph17124545

28.Lopatenko G, Vynogradov V, Yasko L, Chernenko G. Improvement of coordination abilities of qualified athletes specializing in fencing. Pedagogy of Physical Culture and Sports. 2021;25(4):208-214. https://doi.org/10.15561/26649837.2021.0402

29.Fatemeh H. Evaluation of biomechanical indices in elite fencing athletes in the criteria of ankle injury after fleche landing. International Journal of Advanced and Applied Sciences. 2017;4(2):120-127. https://doi.org/10.21833/ijaas.2017.02.020 


\section{Information about the authors:}

Irina Kriventsova; (Corresponding Author); PhD of Pedagogical Sciences, Associate Professor, Head of the Department of Martial Arts, Fencing and Endurance Sports; https://orcid.org/0000-0001-6931-3978; kriventsova.ira@ukr.net; H.S. Skovoroda Kharkiv National Pedagogical University; Kharkiv, Ukraine.

Yevgeniy Gorbachuk; https://orcid.org/0000-0003-4656-1834; eugene.lab98@gmail.com; H.S. Skovoroda Kharkiv National Pedagogical University; Kharkiv, Ukraine.

Svitlana Chernigivs'ka; Assistant Professor; https://orcid.org/0000-0001-7342-438X; kandidat2208@ukr.net; Department of Physical Education and Sports, Dnipro University of Technology; Dnipro, Ukraine.

Marina Jagiello; http://orcid.org/0000-0001-5591-4537; wjagiello1@wp.pl; Department of Theory of Sport and Human Motority, Gdansk University of Physical Education and Sport; Gdansk, Poland.

Abdelkrim Bensbaa; PhD. Physical Education and Sport, Scientific researcher; https://orcid.org/0000-0002-0931-1847; benleone@gmail.com; Military Center of Sport Training; Abu Dhabi, United Arab Emirates.

Cite this article as:

Kriventsova I, Gorbachuk Y, Chernihivska S, Jagiello M, Bensbaa A. Improving the means and methods of training of young fencers aged 9-11 years. Pedagogy of Physical Culture and Sports, 2021;25(6):388-394. https://doi.org/10.15561/26649837.2021.0608

This is an Open Access article distributed under the terms of the Creative Commons Attribution License, which permits unrestricted use, distribution, and reproduction in any medium, provided the original work is properly cited (http://creativecommons.org/licenses/by/4.0/deed.en).

Received: 10.07.2021

Accepted: 23.08.2021; Published: 30.12.2021 